\title{
Association of NPRA and NPRC gene variants and hypertension in Mongolian population
}

\author{
P.Y. Chang', Z.Y. Liu², L. Qin² and P. Zhao ${ }^{3}$ \\ 1'Department of Nuclear Medicine, Inner Mongolia Medical University Affiliated Hospital, \\ Hohhot, China \\ 2Department of Pathophysiology, Inner Mongolia Medical University, Hohhot, China \\ ${ }^{3}$ Department of Cardiology, Inner Mongolia Autonomous Region People's Hospital, \\ Hohhot, China
}

Corresponding author: P. Zhao

E-mail: zhaohshikong@126.com

Genet. Mol. Res. 14 (4): 18494-18502 (2015)

Received August 7, 2015

Accepted October 28, 2015

Published December 23, 2015

DOI http://dx.doi.org/10.4238/2015.December.23.37

ABSTRACT. NPRA and NPRC are candidate susceptibility genes for essential hypertension $(E H)$ and play a key role in the regulation of plasma levels and biological effects of natriuretic peptides. The aims of the present study were to find new genetic markers in the NPRA and NPRC genes and to assess relationships between variants and $\mathrm{EH}$. A total of 797 unrelated Mongolian herdsmen were enrolled, including $389 \mathrm{EH}$ patients and 408 normotensive controls. Genotyping was performed using the polymerase chain reaction/ligase detection reaction assay. The distribution of the T-allele frequency of rs 1847018 in NPRC differed significantly between hypertensive subjects and controls. There was an association between rs 1847018 and $\mathrm{EH}$ in the additive model in NPRC $(\mathrm{P}<0.05)$. There were no significant differences in the genotype and allele frequency distributions for any of the 3 single nucleotide polymorphisms in NPRA between EH and normotensive individuals. In NPRA, the frequency of haplotype TCA in the $\mathrm{EH}$ group was significantly lower than in controls, while the frequency of haplotype TCG was significantly higher in the EH group than in controls; Individuals who possessed the TCA haplotype had a significantly lower 
risk of EH, whereas the presence of haplotype TCG was significantly associated with a higher risk of $\mathrm{EH}$. However, there was no significant difference between the EH group and controls in any of the 8 haplotypes in NPRC. Rs 1847018 is a genetic marker of $\mathrm{EH}$ in NPRC, and the frequency of haplotype TCA and TCG in NPRA is associated with EH in the Mongolian population.

Key words: Essential hypertension; Mongolian population; NPRA, NPRC; Haplotype

\section{INTRODUCTION}

Hypertension is a major cardiovascular risk factor with a global prevalence of $26.4 \%$ in 2000 , projected to increase to $29.2 \%$ by 2025 , and is the leading contributor to global mortality (Kearney et al., 2005). Genetic and environmental factors and their interaction determine an individual's risk for hypertension. Considerable efforts have been made to elucidate the genetic determinants of hypertension, or elevated blood pressure (BP) levels. A body of evidence suggests that A-type natriuretic peptide receptor (NPRA, NPR1) and C-type natriuretic peptide receptor (NPRC, NPR3) are associated with hypertension (Pitzalis et al., 2003; Tsezou et al., 2008; Liu et al., 2012). NPRA and NPRC are receptors of ANP and BNP; ANP and BNP counterbalance the actions of the renin-angiotensin-aldosterone and neurohormonal systems and play a central role in cardiovascular regulation. These activities are mediated by NPRA and NPRC. NPRA is a single transmembrane segment receptor linked to its intrinsic guanylate cyclase (GC) activity in the intracellular domain. Binding of ANP or BNP stimulates GC activity and elevates intracellular levels of cGMP, which in turn elicits physiologic responses through cGMP-regulated ion-channels, protein kinases, phosphodiesterases, and possibly other effector proteins (Kunio et al., 2011). NPRC acts as a clearance receptor for circulating natriuretic peptides $A$ and $B$, and also elicits a number of vascular, renal, and endocrine effects directly via its coupling to an inhibitory heterotrimeric $G$ protein. NPRC is important in the maintenance of BP and extracellular fluid volume. NPRC knockout mice show reduced clearance of circulating natriuretic peptides and have lower BP (Matsukawa et al., 1999).

There have been many studies on the NPRA and NPRC genes and hypertension. Studies in the Mongolian population will allow us to assess the relevance of these findings to this special group and potentially discover novel variants, which is important because some variants may be more common in specific ethnic groups. The aims of the present study were to find new genetic markers in the NPRA and NPRC genes and to assess relationships between variants and phenotypes of essential hypertension $(\mathrm{EH})$ in the Mongolia population.

\section{MATERIAL AND METHODS}

\section{Study population}

The study population aged 20-70 years was recruited from the Duolun and Dongwuqi of Xilin Gol League in Inner Mongolia. A total of 797 unrelated Mongolian herdsmen were enrolled, including 389 Mongolian EH patients and 408 Mongolian normotensives (controls). Each subject 
was from a family that had been living in the area for at least three generations without a history of mixed marriage. Hypertension status was defined as systolic blood pressure (SBP) $\geq 140 \mathrm{mmHg}$ and/ or diastolic blood pressure (DBP) $\geq 90 \mathrm{mmHg}$ or antihypertension treatment. The normotensive group was selected based on the following criteria: SBP $<140 \mathrm{mmHg}$ and $\mathrm{DBP}<90 \mathrm{mmHg}$ and no previous diagnosis of EH. Subjects with a history of secondary hypertension, stroke, coronary heart disease, diabetes, kidney failure, thyroid gland disease, or excessive drinking were excluded from this study.

\section{Phenotype measurements}

The subjects were seated in a quiet room and prevented from smoking, exercising or drinking alcohol, tea or coffee for at least $1 \mathrm{~h}$ before the physical examination. During a clinical examination, demographic information was collected by interview. Weight and height were measured using standard methods as follows. Body weight and height were measured with subjects wearing only light indoor clothing and no shoes. Body mass index (BMI) was calculated by dividing weight $(\mathrm{kg})$ by height squared $\left(\mathrm{m}^{2}\right)$. BP was measured three times, with a 2-min interval between each measurement. SBP was recorded to the nearest $2 \mathrm{mmHg}$ at the appearance of the first Korotkoff sound (phase I), and DBP was recorded to the nearest $2 \mathrm{mmHg}$ at the disappearance of the fifth Korotkoff sound (phase V). The SBP and DBP values were calculated as the means of three consecutive physician-obtained measurements. Blood samples were collected after an overnight fast, and total plasma cholesterol (TC), triglycerides (TG), high-density lipoprotein cholesterol (HDL-C), and low-density lipoprotein cholesterol (LDL-C) were measured within $8 \mathrm{~h}$ in a local hospital. Informed consent was obtained from all subjects.

\section{Selection of single nucleotide polymorphisms (SNPs)}

Tagging SNPs were selected from the Chinese HapMap database (http://www.hapmap. org) based on pairwise $r^{2} \geq 0.8$, minor allele frequency (MAF) $\geq 0.05$. In this study, we chose 3 tagSNPs of NPRA (rs11264232, rs9662664 and rs1008223) and 9 tagSNPs of NPRC (rs3792758, rs16890293, rs10075794, rs1147225, rs2292025, rs1847018, rs976576, rs1060559 and rs696831).

\section{Genotyping}

Genomic DNA was extracted from leukocytes in peripheral blood samples using a commercial blood DNA extraction kit (TIANamp Blood DNA kit; TIANGEN BIOTECH, Beijing, China) and was stored at $-20^{\circ} \mathrm{C}$. All genotyping was performed using the polymerase chain reaction (PCR)/ligase detection reaction assay. Primers were synthesized by Shanghai HAYU Biological Engineering LTD. Each set of ligase detection reaction probes comprised one common probe and two discriminating probes for the two types.

The target DNA sequences were amplified using a multiplex PCR method. PCR for each subject was carried out in a final volume of $20 \mu \mathrm{L}$, containing 1 X PCR buffer, $3.0 \mathrm{mM} \mathrm{MgCl}, 2.0$ $\mathrm{mM}$ deoxynucleotide triphosphate, $2 \mu \mathrm{L}$ primers, $0.2 \mu \mathrm{L}$ Qiagen HotStarTaq Polymerase (QIAGEN, Shenzhen, China), $4 \mu \mathrm{L} 1 \mathrm{X}$ Q-solution, and $50 \mathrm{ng}$ genomic DNA. Thermal cycling was performed in a Gene Amp PCR system 9600 (Norwalk, CT.06859 USA) with an initial denaturation of 2 min at $95^{\circ} \mathrm{C}$, followed by 30 cycles of denaturation at $94^{\circ} \mathrm{C}$ for $30 \mathrm{~s}$, annealing at $50^{\circ} \mathrm{C}$ for $1 \mathrm{~min} 30 \mathrm{~s}$, and extension at $65^{\circ} \mathrm{C}$ for $1 \mathrm{~s}$, with a final extension at $65^{\circ} \mathrm{C}$ for $1 \mathrm{~min}$. 
The ligation reaction for each subject was carried out in a final volume of $10 \mu \mathrm{L}$, containing 1X NEB Taq DNA ligase buffer, $2 \mathrm{pmol}$ of each probe mix, $0.05 \mu \mathrm{L}$ Taq DNA ligase (BIOWING, Jiangsu, China), and $4 \mu \mathrm{L}$ multi-PCR product. A total of 40 cycles for ligase detection reaction were performed with $95^{\circ} \mathrm{C}$ for $2 \mathrm{~min}, 94^{\circ} \mathrm{C}$ for $15 \mathrm{~s}$ and $50^{\circ} \mathrm{C}$ for $2 \mathrm{~s}$. The fluorescent products of the ligase detection reaction were differentiated using an ABI PRISM 3730 analyzer (Applied Biosystems, USA).

\section{Statistical analysis}

The Statistical Program for Social Sciences (SPSS version 11.0) was used to carry out statistical analysis. Hardy-Weinberg equilibrium was determined in each group using the chi-square test. Allele and genotype frequencies between groups were determined using SHEsis software (Shi and He, 2005). We also used the SHEsis software to calculate the coefficient D' of linkage disequilibrium (LD) and to construct haplotypes. Haplotypes with frequencies $<3 \%$ in the whole sample were considered to be rare. There was a strong LD when $\mathrm{D}^{\prime}>0.8$.

\section{RESULTS}

\section{Clinical characteristics of EH and control subjects}

The characteristics of the $\mathrm{EH}$ and control subjects are shown in Table 1. Significant differences in age, SBP, DBP, BMI, TC, TG, HDL-C and LDL-C were observed between EH patients and controls $(P<0.01)$. There was no significant difference between the groups in gender.

\begin{tabular}{|c|c|c|c|}
\hline & $\mathrm{HT}(\mathrm{N}=389)$ & NT $(\mathrm{N}=408)$ & $P$ \\
\hline Male/female & 197/192 & $191 / 217$ & 0.07 \\
\hline Age (year) & $42.00 \pm 16.00$ & $51.00 \pm 18.00$ & $0.00^{* *}$ \\
\hline $\mathrm{SBP}(\mathrm{mmHg})$ & $155.47 \pm 13.94$ & $120.45 \pm 12.22$ & $0.00^{* *}$ \\
\hline $\mathrm{DBP}(\mathrm{mmHg})$ & $92.34 \pm 10.60$ & $73.39 \pm 8.59$ & $0.00^{\text {** }}$ \\
\hline BMI $\left(\mathrm{kg} / \mathrm{m}^{2}\right)$ & $27.78 \pm 3.97$ & $24.96 \pm 3.71$ & $0.00^{* *}$ \\
\hline $\mathrm{TC}(\mathrm{mM})$ & $5.00 \pm 1.05$ & $4.66 \pm 0.86$ & $0.00^{* *}$ \\
\hline $\mathrm{TG}(\mathrm{mM})$ & $2.02 \pm 1.32$ & $1.50 \pm 1.17$ & $0.00^{* *}$ \\
\hline $\mathrm{HDL}(\mathrm{mM})$ & $1.24 \pm 0.23$ & $1.34 \pm 0.36$ & $0.00^{* *}$ \\
\hline $\mathrm{LDL}(\mathrm{mM})$ & $3.27 \pm 0.63$ & $2.95 \pm 0.54$ & $0.00^{+*}$ \\
\hline
\end{tabular}

\section{Single-locus association study of tagSNPs and EH}

Genotype frequencies of all 3 tagSNPs of NPRA and 9 tagSNPs of NPRC were in HardyWeinberg equilibrium both in $\mathrm{EH}$ and controls $(P>0.05)$. The genotype and allele frequency distributions are shown in Table 2. The distribution of allele frequency of rs 1847018 in NPRC differed significantly between the EH group (16.8\%) and control group (12.2\%). There was an association between rs1847018 and $\mathrm{EH}$ in the Mongolian population in the additive model $(\mathrm{P}<$ $0.05)$, and there were no significant difference was found in the genotype and allele frequency distributions between the EH group and controls in other tagSNPs in NPRC $(P>0.05)$. There were 
no significant differences in the genotype and allele frequency distributions for any of the 3 SNPs in NPRA between the EH group and controls.

\begin{tabular}{|c|c|c|c|c|c|}
\hline Gene & Genetype/allele & ET [N (\%)] & NT [N (\%)] & $x^{2}$ & $\mathrm{P}$ \\
\hline \multirow[t]{5}{*}{ rs16890293 } & GG & $260(0.670)$ & $276(0.678)$ & 0.71 & 0.70 \\
\hline & GT & $109(0.281)$ & $116(0.285)$ & & \\
\hline & TT & $30(0.108)$ & $18(0.076)$ & & \\
\hline & G & $629(0.811)$ & $668(0.821)$ & 0.27 & 0.60 \\
\hline & $\mathrm{T}$ & $147(0.189)$ & $146(0.179)$ & & \\
\hline \multirow[t]{5}{*}{ rs696831 } & $\mathrm{CC}$ & $253(0.652)$ & $265(0.651)$ & 0.30 & 0.86 \\
\hline & CT & $121(0.312)$ & $130(0.319)$ & & \\
\hline & TT & $14(0.036)$ & $12(0.029)$ & & \\
\hline & C & $627(0.808)$ & $660(0.811)$ & 0.02 & 0.89 \\
\hline & $\mathrm{T}$ & $149(0.192)$ & $154(0.189)$ & & \\
\hline \multirow[t]{5}{*}{ rs 1847018} & $\mathrm{CC}$ & $283(0.690)$ & $316(0.776)$ & 7.75 & $0.02^{*}$ \\
\hline & CT & $116(0.283)$ & $83(0.204)$ & & \\
\hline & TT & $11(0.027)$ & $8(0.020)$ & & \\
\hline & c & $682(0.832)$ & $715(0.878)$ & 7.71 & $0.01^{* \star}$ \\
\hline & T & $138(0.168)$ & $99(0.122)$ & & \\
\hline \multirow[t]{5}{*}{ rs976576 } & AA & $172(0.443)$ & $179(0.440)$ & 0.12 & 0.94 \\
\hline & AG & $161(0.415)$ & $173(0.425)$ & & \\
\hline & GG & $55(0.142)$ & $55(0.135)$ & & \\
\hline & A & $505(0.651)$ & $531(0.652)$ & 0.99 & 0.95 \\
\hline & G & $271(0.349)$ & $283(0.348)$ & & \\
\hline \multirow[t]{4}{*}{ rs2292025 } & AG & $16(0.041)$ & $13(0.032)$ & 0.49 & 0.48 \\
\hline & GG & $372(0.959)$ & $394(0.968)$ & & \\
\hline & A & $16(0.021)$ & $13(0.016)$ & 0.47 & 0.49 \\
\hline & G & 760 (0.979) & $801(0.984)$ & & \\
\hline \multirow[t]{5}{*}{ rs1147225 } & AA & $146(0.379)$ & $160(0.394)$ & 3.32 & 0.19 \\
\hline & AG & $199(0.517)$ & $189(0.466)$ & & \\
\hline & GG & $40(0.104)$ & $57(0.140)$ & & \\
\hline & A & $491(0.638)$ & $509(0.627)$ & 0.20 & 0.66 \\
\hline & G & $279(0.362)$ & $303(0.373)$ & & \\
\hline \multirow[t]{5}{*}{ rs 3792758} & GG & $234(0.608)$ & $239(0.589)$ & 0.42 & 0.81 \\
\hline & GT & $131(0.340)$ & $147(0.362)$ & & \\
\hline & TT & $20(0.052)$ & $20(0.049)$ & & \\
\hline & G & $599(0.778)$ & $625(0.770)$ & 1.04 & 0.70 \\
\hline & $\mathrm{T}$ & $171(0.222)$ & $187(0.230)$ & & \\
\hline \multirow[t]{5}{*}{ rs10075794 } & $\mathrm{CC}$ & $23(0.059)$ & $16(0.040)$ & 1.66 & 0.44 \\
\hline & СT & $124(0.320)$ & $134(0.332)$ & & \\
\hline & TT & $241(0.621)$ & 254 (0.629) & & \\
\hline & C & $170(0.219)$ & $166(0.205)$ & 0.43 & 0.51 \\
\hline & $\mathrm{T}$ & $606(0.781)$ & $642(0.795)$ & & \\
\hline \multirow[t]{4}{*}{ rs1060559 } & $\mathrm{CC}$ & $370(0.954)$ & $391(0.968)$ & 1.06 & 0.30 \\
\hline & CT & $18(0.046)$ & $13(0.032)$ & & \\
\hline & c & $758(0.977)$ & $795(0.984)$ & 1.04 & 0.31 \\
\hline & $\mathrm{T}$ & $18(0.023)$ & $13(0.016)$ & & \\
\hline \multirow{5}{*}{ rs9662664 } & GG & $152(0.393)$ & $169(0.415)$ & 0.89 & 0.64 \\
\hline & GT & $184(0.475)$ & $180(0.442)$ & & \\
\hline & TT & $51(0.132)$ & $58(0.143)$ & & \\
\hline & G & $488(0.630)$ & $518(0.636)$ & 0.05 & 0.81 \\
\hline & $\mathrm{T}$ & $286(0.370)$ & $296(0.364)$ & & \\
\hline \multirow[t]{4}{*}{ rs1008223 } & $\mathrm{CC}$ & $368(0.951)$ & $388(0.953)$ & 0.03 & 0.87 \\
\hline & CT & $19(0.049)$ & $19(0.047)$ & & \\
\hline & $\mathrm{c}$ & $755(0.975)$ & $795(0.977)$ & 0.02 & 0.88 \\
\hline & $\mathrm{T}$ & $19(0.025)$ & $19(0.023)$ & & \\
\hline \multirow[t]{5}{*}{ rs 1126423} & AA & $7(0.018)$ & $11(0.027)$ & 4.52 & 0.10 \\
\hline & AG & $90(0.234)$ & $119(0.293)$ & & \\
\hline & GG & $287(0.747)$ & $276(0.680)$ & & \\
\hline & A & $104(0.135)$ & $141(0.174)$ & 4.40 & 0.04 \\
\hline & G & $664(0.865)$ & $671(0.826)$ & & \\
\hline
\end{tabular}

$\mathrm{HT}=$ hypertensive; $\mathrm{NT}=$ normotensives. ${ }^{*} \mathrm{P}<0.05,{ }^{* *} \mathrm{P}<0.01$. 


\section{Haplotypes of tagSNPs}

LD among the tagSNPs was measured by the Lewontin standardized disequilibrium coefficient D' in NPRA and NPRC, respectively (Slatkin, 2008). In NPRA, three loci (rs9662664, rs1008223 and rs1126423) were found to be in strong LD (D'>0.8) (Table 3). In NPRC, three loci (rs16890293, rs1147225 and rs10075794) were found to be in strong LD (D' > 0.8) (Table 4). Using the SHEsis software, we found that there were 5 haplotypes in NPRA and 8 haplotypes in NPRC. In NPRA, the frequency of haplotype TCA in the EH group (13.3\%) was significantly lower than in the control group $(17.0 \%)$, the frequency of haplotype TCG was significantly higher in the EH group $(21.2 \%)$ than in controls $(17.1 \%)$. Individuals who possessed the TCA haplotype had a significantly lower risk of EH, whereas the presence of haplotype TCG was significantly associated with a higher risk of $\mathrm{EH}$. However, in NPRC, there was no significant difference between $\mathrm{EH}$ group and controls in any of the 8 haplotypes.

\begin{tabular}{|c|c|c|c|c|c|c|}
\hline Haplotype & $\mathrm{HT}[\mathrm{N}(\%)]$ & NT [N (\%)] & $x^{2}$ & OR & $95 \% \mathrm{Cl}$ & $P$ \\
\hline GCA & $1.33(0.002)$ & & $2.42(0.003)$ & & & \\
\hline GCG & $482.67(0.630)$ & $512.58(0.633)$ & 0.02 & 0.984 & $0.798-1.214$ & 0.88 \\
\hline TCA & $101.67(0.133)$ & $137.58(0.170)$ & 4.277 & 0.746 & $0.565-0.985$ & $0.04^{*}$ \\
\hline TCG & $162.33(0.212)$ & $138.42(0.171)$ & 4.269 & 1.305 & $1.013-1.680$ & $0.04^{*}$ \\
\hline TTG & $18.00(0.023)$ & $19.00(0.023)$ & & & & \\
\hline Globe $x^{2}$ & 7.05 & & & & & \\
\hline Fisher $\mathrm{P}$ & $0.03^{*}$ & & & & & \\
\hline
\end{tabular}

$\mathrm{HT}=$ hypertensives; NT = normotensives; $\mathrm{OR}=$ odds ratio; $\mathrm{Cl}=$ confidence interval; $\mathrm{X}^{2}=$ Pearson's chi-square. ${ }^{*} \mathrm{P}<0.05$.

\begin{tabular}{|c|c|c|c|c|c|c|}
\hline Haplotype & $\mathrm{HT}[\mathrm{N}(\%)]$ & NT [N (\%)] & $x^{2}$ & OR & $95 \% \mathrm{Cl}$ & $P$ \\
\hline $\mathrm{GAC}^{*}$ & $26.14(0.032)$ & $24.63(0.031)$ & 0.028 & 1.049 & $0.600-1.835$ & 0.86 \\
\hline $\mathrm{GAT}^{*}$ & $337.72(0.416)$ & $336.20(0.418)$ & 0.022 & 0.985 & $0.808-1.201$ & 0.87 \\
\hline G G C & $0.00(0.000)$ & $1.53(0.002)$ & & & & \\
\hline$G G T^{*}$ & $291.15(0.359)$ & $297.64(0.370)$ & 0.288 & 0.946 & $0.772-1.159$ & 0.59 \\
\hline $\mathrm{TAC}^{*}$ & $152.83(0.188)$ & $138.82(0.173)$ & 0.613 & 1.107 & $0.859-1.427$ & 0.43 \\
\hline TAT & $1.32(0.002)$ & $3.35(0.004)$ & & & & \\
\hline T G C & $0.03(0.000)$ & $0.02(0.000)$ & & & & \\
\hline $\mathrm{T} \mathrm{G} \mathrm{T}$ & $2.83(0.004)$ & $1.81(0.002)$ & & & & \\
\hline Globe $x^{2}$ & 0.72 & & & & & \\
\hline Fisher $\mathrm{P}$ & 0.87 & & & & & \\
\hline
\end{tabular}

HT = hypertensives; NT = normotensives; OR = odds ratio; $\mathrm{Cl}=$ confidence interval; $\mathrm{X}^{2}=$ Pearson's chi-square.

\section{DISCUSSION}

There are three types of natriuretic peptides (NP), atrial natriuretic peptide (ANP), brain natriuretic peptide (BNP), and C-type natriuretic peptide (CNP). The NP family elicits a number of vascular, renal and endocrine effects that help to maintain BP and extracellular fluid volume. NP biological effects are mediated by 3 membrane receptors: NPRA, NPRB and NPRC. NPRA is preferentially activated by ANP and BNP; NPRC is involved in the clearance of all NP from the blood (Potter et al., 2006). The NP hormone family includes various proteins characterized by similar 
chemical structure and shared biological functions, with important effects on the cardiovascular system. Accordingly, these molecules are widely recognized as key clinical biomarkers in the diagnosis and monitoring of heart failure, hypertension, and coronary heart disease.

The natriuretic peptide receptor A (NPRA, NPR1) gene is located on chromosome 1q2122, composed of 22 exons, and is about $16 \mathrm{~kb}$ long (Takahashi et al., 1998). Several SNPs have

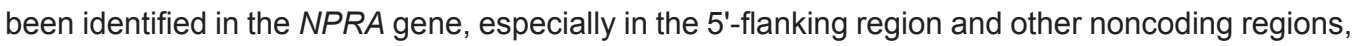
which may influence the transcriptional activity of the gene and may thus be potentially involved in the pathogenesis of EH and other cardiovascular diseases (Pitzalis et al., 2003; Rubattu et al., 2004). Knowles et al. (2003) found that common NPRA alleles can alter the expression of the gene and could therefore significantly affect genetic risks for EH in humans. In the Japanese population, an 8-bp deletion in the 5'-flanking region of NPRA may increase the susceptibility to developing EH or left ventricular hypertrophy (Nakayama et al., 2000). In another study by the same authors, a missense mutation, M341I, consisting of a methionine (ATG) to isoleucine (ATC) substitution at nucleotide 1023 in exon 3, was identified and shown to be associated with EH (Nakayama et al., 2002). The (CT)n polymorphism in the $5^{\prime}$-flanking region of the NPRA gene also was found to be significantly associated with $\mathrm{EH}$, probably through the downregulation of NPRA gene transcription (Usami et al., 2008). In a Greek population, no association between NPRA gene polymorphisms and hypertension were found (Tsezou et al., 2008).

Genetic variation in NPRC has been associated with BP regulation. Aoi et al. (2004) examined the association between variable number of tandem repeat (VNTR) and hypertension, and their results suggested that the VNTR of the 5'-flanking region of the NPRC gene influences BP levels in obesity-associated hypertension. The genome-wide association study of SBP and DBP in 200,000 individuals of European descent, identified sixteen novel loci, including NPR3C5orf23, that were associated with BP (International Consortium for Blood Pressure Genome-Wide Association Studies et al., 2011). A meta-analysis of genome-wide association studies of SBP and DBP in 19,608 subjects of East Asian ancestry from the AGEN-BP consortium highlighted the possible importance of this gene in BP control (Kato et al., 2011). Fedorowski et al. (2012) found that the NPR3-C5orf23 (rs1173771) locus was associated with orthostatic hypotension. Saulnier et al. (2011) assessed the association between NPR3 gene polymorphisms and BP levels in patients with type 2 diabetes, they found three SNPs (rs6889608, rs1173773, and rs2270915) significantly associated with SBP, and they found a significant association between the rs2270915 polymorphism of the NPR3 gene and SBP in diabetic patients. A case-control study in a Chinese Han population found that rs 16890208 and rs700925 in NPR3 were associated with hypertension. Furthermore, they found that rs 11745562 and rs2270915 in NPR3, in LD with each other in intron 5 and exon 8, were associated with hypertension (Liu et al., 2012).

In this study, we examined the relationships between tagSNPs of NPRA, NPRC gene and $\mathrm{EH}$ in the Mongolian population, we found that there was an association between rs1847018 of NPRC and EH in the Mongolian population. The mechanisms by which rs 1847018 may contribute to hypertension are currently unknown. There were no significant differences in the genotype and allele frequency distributions for any of the 3 SNPs between the EH group and controls in NPRA. In haplotype analysis of NPRA, individuals who possessed the TCA haplotype had a significantly lower risk of EH, whereas the presence of haplotype TCG was significantly associated with a higher risk of $\mathrm{EH}$. However, there was no significant difference between $\mathrm{EH}$ group and controls in any of the 8 haplotypes in NPRC.

From the above, we can see that the correlation between the NPRA and NPRC genes and 
hypertension was different in different ethnic groups. Genetic heterogeneity between populations could be the cause of these conflicting results. In addition to different genetic backgrounds between ethnic groups, variation in environmental factors and gene-environment interactions could also play an important role. Mongolians have one of the highest prevalence rates of hypertension in all ethnic groups of China, ranking among the top 5. Xilin Gol League of Inner Mongolia in China is a gathering area of the Mongolian population. There is a desert with an arid and cold climate in Xilin Gol League. The local Mongolian herdsmen like to drink milk tea, and they are used to adding salt to the tea, which leads to an exceptionally high sodium intake. This practice has been related to renal salt retention, extracellular volume expansion and volume hypertension.

In conclusion, rs1847018 was found to be a potential genetic marker of EH in NPRC, and the TCA and TCG haplotypes in NPRA were associated with EH in the Mongolian population. These findings may help find ways to prevent and treat $\mathrm{EH}$ in the Mongolian population in Inner Mongolia.

\section{ACKNOWLEDGMENTS}

Research supported by the Inner Mongolian Science \& Technology Plan and Chinese Academy of Sciences, "Western Light" Training Program, Duolun Center for Disease Prevention and Control, and the Department of Epidemiology of the Inner Mongolia University.

\section{REFERENCES}

Aoi N, Soma M, Nakayama T, Rahmutula D, et al. (2004). Variable number of tandem repeat of the 5'_flanking region of type-C human natriuretic peptide receptor gene influences blood pressure levels in obesity-associated hypertension. Hypertens. Res. 27: 711-716.

Fedorowski A, Franceschini N, Brody J, Liu C, et al. (2012). Orthostatic hypotension and novel blood pressure-associated gene variants: Genetics of Postural Hemodynamics (GPH) Consortium. Eur. Heart J. 33: 2331-2341.

International Consortium for Blood Pressure Genome-Wide Association Studies, Ehret GB, Munroe PB, Rice KM, et al. (2011). Genetic variants in novel pathways influence blood pressure and cardiovascular disease risk. Nature 478: 103-109.

Kato N, Takeuchi F, Tabara Y, Kelly TN, et al. (2011). Meta-analysis of genome-wide association studies identifies common variants associated with blood pressure variation in east Asians. Nat. Genet. 43: 531-538.

Kearney PM, Whelton M, Reynolds K, Muntner P, et al. (2005). Global burden of hypertension: analysis of worldwide data. Lancet 365: 217-223.

Knowles JW, Erickson LM, Guy VK, Sigel CS, et al. (2003). Common variations in noncoding regions of the human natriuretic peptide receptor A gene have quantitative effects. Hum. Genet. 112: 62-70.

Liu Y, Li S, Chen X, Zheng L, et al. (2012). Association of natriuretic Peptide receptor-C gene with ischemic stroke and hypertension in Chinese Han population. Clin. Exp. Hypertens. 34: 504-509.

Matsukawa, N, Grzesik, WJ, Takahashi, N, et al. (1999). The natriuretic peptide clearance receptor locally modulates the physiological effects of the natriuretic peptide system. Proc. Natl. Acad. Sci. U. S. A. 96: 7403-7408.

Misono KS, Philo JS, Arakawa T, Ogata CM, et al. (2011). Structure, signaling mechanism and regulation of natriuretic peptide receptor-guanylate cyclase. FEBS J. 278: 1818-1829.

Nakayama T, Soma M, Takahashi Y, Rehemudula D, et al. (2000). Functional deletion mutation of the 5_flanking region of type A human natriuretic peptide receptor gene and its association with essential hypertension and left ventricular hypertrophy in the Japanese. Circ. Res. 86: 841-845.

Nakayama T, Soma M, Mizutani Y, Xinjuan X, et al. (2002). A novel missense mutation of exon 3 in the type A human natriuretic peptide receptor gene: possible association with essential hypertension. Hypertens. Res. 25: 395- 401.

Pitzalis MV, Sarzani R, Dessì-Fulgheri P, lacoviello M, et al. (2003). Allelic variants of natriuretic peptide receptor genes are associated with family history of hypertension and cardiovascular phenotype. J. Hypertens. 21:1491-1496.

Potter LR, Abbey-Hosch S and Dickey DM (2006). Natriuretic peptides, their receptors, and cyclic guanosine monophosphatedependent signaling functions. Endocr. Rev. 27: 47-72.

Rubattu S, Stanzione R, Di Angelantonio E, Zanda B, et al. (2004). Atrial natriuretic peptide gene polymorphisms and risk of ischemic stroke in humans. Stroke 35: 814-818. 
Saulnier PJ, Roussel R, Halimi JM, Lebrec J, et al. (2011). Impact of natriuretic peptide clearance receptor (NPR3) gene variants on blood pressure in type 2 diabetes. Diabetes Care 34: 1199-1204.

Shi YY and He L (2005). SHEsis, a powerful software platform for analyses of linkage disequilibrium, haplotype construction, and genetic association at polymorphism loci. Cell Res. 15: 97-98.

Slatkin M (2008). Linkage disequilibrium-understanding the evolutionary past and mapping the medical future. Nat. Rev. Genet. 9: $477-485$.

Takahashi Y, Nakayama T, Soma M, Izumi Y, et al. (1998). Organization of the human natriuretic peptide receptor A gene. Biochem. Biophys. Res. Commun. 246: 736-739.

Tsezou A, Karayannis G, Giannatou E, Papanikolaou V, et al. (2008). Association of renin-angiotensin system and natriuretic peptide receptor A gene polymorphisms with hypertension in a Hellenic population. J. Renin Angiotensin Aldosterone Syst. 9: 202-207.

Usami S, Kishimoto I, Saito Y, Harada M, et al. (2008). Association of CT dinucleotide repeat polymorphism in the 5_flanking region of the guanylyl cyclase (GC): a gene with essential hypertension in the Japanese. Hypertens. Res. 31: 89-96. 